\title{
Comparative Analysis of Anthropometric Characteristics between Athlets of Different Orientation
}

\author{
Marina Vukotic ${ }^{1}$, Georgi Georgiev ${ }^{2}$ \\ 'University of Montenegro, Faculty for Sport and Physical Education, Niksic, Montenegro, ${ }^{2}$ St. Cyril and Methodius University, Faculty for Physical \\ Education, Sport and Health, Skopje, Macedonia
}

\section{Abstract}

The main goal of this research is to determine whether there are statistically significant differences in the level of anthropometric indicators among athletes of different sports directions (basketball and volleyball players), that is, to determine the differences in the changes in the anthropometric indicators of athletes. In accordance with the goal, a transversal study was conducted in which the empirical and statistical methods were applied, and the research technique was testing. The study was conducted on a sample of 50 subjects, a male sex divided into two subunits, an age range of 13 to 15 years. In this study, 12 anthropometric variables were tested: body height, arm length, leg length, knee diameter, bicrystalline range, bichromium range, body mass, median volume of the thorax, circumference, upper abdomen, skin abdomen and skin set of lower legs. For all applied variables, the central and dispersion parameters as well as measures of asymmetry and flattening were calculated, and the distribution normality was verified by Kolmogorov-Smirnov test. T-test was applied to verify that the system of applied variables has statistically quantitative differences between groups. For the determination of the differences between the group of variables and the group of subjects, discriminatory. On the basis of the obtained results, it can be concluded that there are statistically significant differences in anthropometric indicators in athletes of different sports orientations. This research can be used by trainers who realize training programs with these and other athletes in order to achieve better results.
\end{abstract}

Key words: Basketball, Volleyball, Anthropometric Characteristics, Montenegro

\section{Uvod}

U današnjim uslovima života i rada sport predstavlja veoma važno područje u kojem čovjek na specifičan način može ispoljiti svoje prije svega, stvaralačke kretne strukture (Bjelica, 2005; Vukotić, 2010). Sport u savremenim uslovima života predstavlja složen sistem različitih aktivnosti i oblika organizovanja kroz koje se ispoljavaju brojne i različite potrebe i interesi sportista (Bjelica, 2002; Vukotić, Ćorluka, Vasiljević, i Bubanja, 2018). Zadovoljenje sportskih potreba i interesa značajno je sa aspekta zdravlja, svestranog razvoja ličnosti sportiste, podizanja radne sposobnosti do nivoa sportske forme, te sposobnosti za učešće u sistemu takmičenja (Bjelica,
2004; Bjelica, 2006a; Bjelica, 2006b). Smatra se da je jedan od osnovnih motiva koji pokreće ljude da se bave sportom, upravo težnja za usavršavanjem i mjerenjem svojih karakteristika i sposobnosti koje se mogu razviti pod uticajem trenažnog procesa (Bjelica, 2013; Popovic, 2017). Postojanje velikog broja sportova zahtijeva i njihovo klasifikovanje (Masanovic, 2008; Masanovic, 2009). Poznato je da sportski rezultat koji postižu sportisti u velikoj mjeri zavisi od morfoloških karakteristika, pa se navedene karakteristike smatraju najvažnijim dimenzijama latentne strukture antropološkog statusa (Vukasevic, Vukotic, i Masanovic, 2018; Masanovic, Vukotic, i Vukasevic, 2018). Bolje upoznavanje antropometrijskih karakteristika i

\section{Montenegro}

Sport

\section{Correspondence:}

M. Vukotic

University of Montenegro, Faculty for Sport and Physical Education, Niksic, Montenegro

E-mail: marinavuk@ucg.ac.me 
konstitucije sportista ima za cilj: upravljanje ovim svojstvima, prilagođavanje sportskog treninga individualnim sposobnostima i mogućnost prognoziranja krajnjih dometa (Masanovic, Vukotic, Popović, i Bjelica, 2018).

Košarka i odbojka kao sportske igre zahtijevaju različite prethodno navedene dimenzije, a takođe i procese sportskog treninga i obučavanja (Masanović, 2015; Vukotic, 2011; Vukotic, 2018). Za sportske trenere je od posebnog značaja da poznaju zakonitosti rasta i razvoja antropometrijskih karakteristika i motoričkih sposobnosti da bi primjena različitih treninga bila što efikasnija (Bjelica, 2005; Bjelica, Popovic, i Gardasevic, 2016a; Bjelica, Popovic, i Gardasevic, 2016b; Bjelica, Popović, Kezunovic, Petković, Jurak, i Grasgruber, 2012; Bjelica, 2002; Bjelica i Krivokapic, 2010; Bjelica i Krivokapic, 2011; Bjelica i Krivokapic, 2012; Gardasevic i Bjelica, 2013; Gardasevic i Bjelica, 2014; Gardasevic, Popovic, i Bjelica, 2016; Masanovic, Vukotic, Bjelica, i Popovic, 2018; Popovic, Bjelica, Vukotic, i Masanovic, 2018). Morfološke karakteristike su izuzetno značajne za uspjeh u košarci i odbojci (Masanovic, 2018a; Masanovic, Milosevic, \& Corluka, 2018). U prostoru morfoloških dimenzija košarkaša i odbojkaša definisani su posebni faktori označeni kao latentne morfološke dimenzije: longitudinalna dimenzionalnost skeleta, transverzalna dimenzionalnost skeleta, masa i volumen tijela, i potkožno masno tkivo (Bjelica i Fratrić, 2011). Morfološki status vrhunskih sportista su relativno homogeni, u zavisnosti od sporta, i mogu biti definisani kao modeli sportistskog postignuća (Mišigoj-Duraković, Matković, i Medved, 1995). Visina daje prednost u sportskim igrama, jer se cilj nalazi na velikoj visini, takođe visina igračima omogućava da lakše dođu do lopte u odbrani i napadu, blokiraju protivnički napad i šut (Popovic, Bjelica, Jaksic, i Hadzic, 2014). Većina elemenata naročito onih sa loptom su veoma složeni. Za njihovo usvajanje i besprekornu primjenu u igri potreban je visok nivo razvijenosti cjelokupnog motornog aparata (Vukasevic, Vukotic, i Masanovic, 2018).

Osnovni cilj ovog istraživanja je da se utvrdi da li postoje statistički značajne razlike u nivou antropometrijskih karakteristika između sportista različitog sportskog usmjerenja (košarka i odbojka), odnosno da se utvrde razlike u promjenama antropometrijskih karakteristika sportista.

\section{Metod}

Uzorak ovog istraživanja čini ukupno 50 ispitanika, muškog pola podijeljenih na dva subuzorka. Prvi subuzorak su činili 25 dječaka članova Košarkaškog kluba „Sutjeska“, prosječne starsoti13.95 \pm 4.28 godina i drugi subuzorak su činili 25 dječaka članova Odbojkaškog kluba „Volley star“, iz Nikšića, prosječne starosti $14.05 \pm 7.15$ godina.

Antropometrijsko istraživanje sprovedeno je uz poštovanje osnovnih pravila i principa vezanih za izbor mjernih instrumenata i tehnike mjerenja koji su standardizovani, prema upustvima Internacionalnog Biološkog Programa. Odabrane varijable $\mathrm{u}$ ovom istraživanju hipotetski pokrivaju prostor antropometrijskih karakteristika (12) i to: visina tijela (MVI), dužina ruke (MDR), dužina noge (MDN), dijametar koljena (MDK), bikristalni raspon (MBR), biakromijalni raspon (MBI), masa tijela (MMS), srednji obim grudnog koša (MSK), obim natkoljenice $(\mathrm{MON})$, kožni nabor nadlaktice (MKD), kožni nabor trbuha $(\mathrm{MKN})$ i kožni nabor potkoljenice (MKP).

Podaci dobijeni ovim istraživanjem obrađeni su postupcima deskriptivne i komparativne statističke procedure. Za sve primijenjene varijable izračunati su centralni i disperzioni parametri kao i mjere asimetrije i spljoštenosti, a normalnost distribucije provjerena je Kolmogorov-Smirnovljevim testom. Razlike $\mathrm{u}$ antropomerijskim karakteristikama između dvije grupe ispitanika (košarkaša i odbojkaša) utvrđene su primjenom diskriminativne parametrijske procedure, $\mathrm{t}$-testom za male nezavisne uzorke, sa statističkom značajnošću od $\mathrm{p}<0.05$.

\section{Rezultati}

U Tabelama 1 i 2 prikazani su osnovni deskriptivni statistički parametri antropometrijskih varijabli košarkaša i odbojkaša kadetskog uzrasta, gdje su izračunate vrijednosti mjera centralne i disperzione tendencije i to: aritmetička sredina (Mean), standardna devijacija (Std. Dev.), mjera varijabiliteta (KV), minimalne (Min) i maksimalne (Max) vrijednosti, koeficijenti zakrivljenosti (Skewness), izduženosti (Kurtosis) i Kolmogorov-Smirnovljev test (K-S). Prvo su analizirani centralni i disperzioni parametri varijabli za procjenu antropometrijskih karakteristika košarkaša kadeta (Tabela 1.).

Tabela 1. Centralni i disperzioni parametri varijabli za procjenu antropometrijskih karakteristika košarakaša kadetskog uzrasta $(\mathrm{N}=25)$

\begin{tabular}{ccccccccc}
\hline & Mean & S.D. & KV \% & Min & Max & Skewness & Kurtosis & K-S \\
\hline MVI & 180.58 & 6.47 & 3.58 & 169.00 & 191.00 & -0.29 & -0.60 & 0.95 \\
MDR & 79.58 & 3.61 & 4.54 & 71.50 & 85.00 & -0.56 & 0.01 & 0.94 \\
MDN & 101.62 & 4.60 & 4.53 & 91.00 & 109.00 & -0.47 & 0.28 & 0.83 \\
MDK & 8.45 & 0.76 & 8.99 & 6.40 & 9.90 & -0.90 & 1.31 & 0.31 \\
MBR & 38.20 & 3.84 & 10.05 & 33.00 & 51.00 & 1.48 & 4.08 & 0.60 \\
MBI & 40.22 & 3.15 & 7.83 & 34.00 & 46.00 & -0.04 & -0.56 & 0.90 \\
MMS & 65.32 & 11.34 & 17.36 & 49.00 & 94.00 & 1.16 & 0.99 & 0.44 \\
MSK & 85.50 & 6.43 & 7.52 & 77.00 & 97.00 & 0.50 & -1.26 & 0.21 \\
MON & 44.42 & 5.78 & 13.01 & 36.00 & 58.00 & 0.81 & 0.09 & 0.38 \\
MKD & 12.26 & 3.46 & 28.22 & 5.30 & 18.00 & -0.27 & -0.80 & 1.00 \\
MKN & 11.68 & 4.05 & 34.67 & 5.30 & 21.67 & 0.34 & 0.08 & 0.87 \\
MKP & 10.31 & 3.16 & 30.65 & 5.00 & 17.67 & 0.30 & -0.31 & 0.96 \\
\hline
\end{tabular}

Legenda: Mean - Aritmetička sredina; S.D. - Standardna devijacija; KV\% - Mjera varijabiliteta; Min - Minimalna vrijednost; Max - Maksimalna vrijednost; Skewness - Mjera asimetrije; Kurtosis - Mjera spljoštenosti; K-S - Kolmogorov-Smirnovljev test

$\mathrm{Na}$ osnovu dobijenih rezultata utvrđeno je da su rezultati normalno distribuirani (prema K-S testu). Na osnovu centralnih i disperzionih parametara, vrijednosti skjunisa i kurtozisa može se konstatovati da su sve varijable u granicama normal- ne raspodjele. Vrijdnosti skjunisa kod varijabli sa pozitivnim predznakom, govore da su vrijednosti većine ispitanika u zoni slabijih vrijednosti i one su normalno asimetrične ili umjereno asimetrične, dok u mjerama: bikristalni raspon i masa tijela sa 
odgovarajućim vrijednostima 1.48 i 1.16 su izraženo asimetrične. Negativne vrijednosti kurtozisa kod varijabli pokazuju veću spljoštenost (nagnutost) od normalnog oblika, tj. platikurtičnost. To ukazuje na heterogenost dobijenih rezultata, odnosno izraženiju diskriminativnost među ispitanicima.

U mjeri bikristalni raspon (Kurt=4.08) možemo konstatovati da je subuzorak košarkaša homogeniji (leptokurtičnost).

Tabela 2. Centralni i disperzioni parametri varijabli za procjenu antropometrijskih karakteristika odbojkaša kadetskog uzrasta $(\mathrm{N}=25)$

\begin{tabular}{|c|c|c|c|c|c|c|c|c|}
\hline & Mean & S.D. & KV \% & Min & Max & Skewness & Kurtosis & K-S \\
\hline MVI & 178.58 & 8.13 & 4.66 & 161.00 & 190.00 & 0.22 & -0.85 & 0.92 \\
\hline MDR & 76.54 & 3.47 & 4.53 & 70.00 & 85.00 & 0.49 & 0.41 & 0.53 \\
\hline MDN & 98.16 & 5.17 & 5.27 & 88.00 & 109.00 & 0.04 & -0.20 & 0.81 \\
\hline MDK & 8.85 & 0.60 & 6.78 & 7.80 & 10.00 & 0.26 & -0.74 & 0.96 \\
\hline MBR & 35.02 & 2.02 & 5.77 & 31.00 & 39.00 & -0.44 & 0.08 & 0.20 \\
\hline $\mathrm{MBI}$ & 38.72 & 2.85 & 7.36 & 33.00 & 45.00 & 0.09 & 0.25 & 0.39 \\
\hline MMS & 66.28 & 10.60 & 18.83 & 35.00 & 80.00 & -0.12 & 0.05 & 0.90 \\
\hline MSK & 80.20 & 5.44 & 6.78 & 70.00 & 94.00 & 0.21 & 0.71 & 0.98 \\
\hline MON & 42.84 & 3.68 & 8.59 & 34.00 & 52.00 & -0.08 & 1.34 & 0.47 \\
\hline MKD & 10.83 & 2.88 & 26.59 & 6.00 & 16.67 & 0.18 & -0.69 & 0.98 \\
\hline MKN & 8.48 & 3.44 & 40.57 & 4.00 & 18.30 & 1.29 & 1.55 & 0.28 \\
\hline MKP & 7.85 & 2.51 & 31.97 & 2.67 & 11.70 & -0.64 & -0.23 & 0.32 \\
\hline
\end{tabular}

$\mathrm{Na}$ osnovu dobijenih rezultata utvrđeno je da su rezultati normalno distribuirani (prema K-S testu). Na osnovu centralnih i disperzionih parametara, vrijednosti skjunisa i kurtozisa, može se konstatovati da su sve varijable u granicama normalne raspodjele. Vrijednosti skjunisa kod varijabli sa pozitivnim predznakom, govore da su vrijednosti većine ispitanika u zoni slabijih vrijednosti i one su normalno asimetrične ili umjereno asimetrične, dok su u mjeri kožni nabor trbuha sa odgovaraju- ćim vrijednostima 1.29 izraženo asimetrični i u zoni slabijih rezultata. Negativne vrijednosti kurtozisa kod varijabli pokazuju veću spljoštenost (nagnutost) od normalnog oblika, tj. leptokurtičnost. To ukazuje na heterogenost dobijenih rezultata, odnosno izraženiju diskriminativnost među ispitanicima.

Da bi se moglo utvrditi da li ima statistički značajnih razlika u analiziranim varijablama kod košarkaša i odbojkaša kadetskog uzrasta, primjenjena je statistička procedura t-test (Tabela 3).

Tabela 3. Vrijednosti t-testa izmedju aritmetičkih sredina varijabli za procjenu antropometrijskih igrača kadeta košarkaša ( $\mathrm{N}=25)$ i kadeta odbojkaša $(\mathrm{N}=25)$

\begin{tabular}{|c|c|c|c|c|c|c|}
\hline & Group & Mean & S. D. & $t$ & df & Sig. \\
\hline \multirow{2}{*}{ MVI } & Košarka & 180.58 & 6.47 & \multirow{2}{*}{2.89} & \multirow{2}{*}{48} & \multirow{2}{*}{0.01} \\
\hline & Odbojka & 174.58 & 8.13 & & & \\
\hline \multirow{2}{*}{ MDR } & Košarka & 79.58 & 3.61 & \multirow{2}{*}{3.04} & \multirow{2}{*}{48} & \multirow{2}{*}{0.00} \\
\hline & Odbojka & 76.54 & 3.47 & & & \\
\hline \multirow{2}{*}{ MDN } & Košarka & 101.62 & 4.60 & \multirow{2}{*}{2.50} & \multirow{2}{*}{48} & \multirow{2}{*}{0.02} \\
\hline & Odbojka & 98.16 & 5.17 & & & \\
\hline \multirow{2}{*}{ MDK } & Košarka & 8.45 & 0.76 & \multirow{2}{*}{-2.05} & \multirow{2}{*}{48} & \multirow{2}{*}{0.05} \\
\hline & Odbojka & 8.85 & 0.60 & & & \\
\hline \multirow{2}{*}{ MBR } & Košarka & 38.20 & 3.84 & \multirow{2}{*}{3.67} & \multirow{2}{*}{48} & \multirow{2}{*}{0.09} \\
\hline & Odbojka & 35.02 & 2.02 & & & \\
\hline \multirow{2}{*}{$\mathrm{MBI}$} & Košarka & 40.22 & 3.15 & \multirow{2}{*}{1.77} & \multirow{2}{*}{48} & \multirow{2}{*}{0.08} \\
\hline & Odbojka & 38.72 & 2.85 & & & \\
\hline \multirow{2}{*}{ MMS } & Košarka & 65.32 & 11.34 & \multirow{2}{*}{2.91} & \multirow{2}{*}{48} & \multirow{2}{*}{0.01} \\
\hline & Odbojka & 56.28 & 10.60 & & & \\
\hline \multirow{2}{*}{ MSK } & Košarka & 85.50 & 6.43 & \multirow{2}{*}{3.15} & \multirow{2}{*}{48} & \multirow{2}{*}{0.00} \\
\hline & Odbojka & 80.20 & 5.44 & & & \\
\hline \multirow{2}{*}{ MON } & Košarka & 44.42 & 5.78 & 115 & 48 & בטח0 \\
\hline & Odbojka & 42.84 & 3.68 & 1.15 & 48 & 0.02 \\
\hline MKD & Košarka & 12.26 & 3.46 & 158 & 48 & 012 \\
\hline IVIKD & Odbojka & 10.83 & 2.88 & 1.58 & 48 & 0.12 \\
\hline & Košarka & 11.68 & 4.05 & & & \\
\hline MKN & Odbojka & 8.48 & 3.44 & 3.01 & 48 & 0.00 \\
\hline & Košarka & 10.31 & 3.16 & & & \\
\hline МКР & Odbojka & 7.85 & 2.51 & 3.05 & 48 & 0.00 \\
\hline
\end{tabular}

$\mathrm{Na}$ osnovu rezultata se može vidjeti da je došlo do kvantitativnih promjena, što nam potvrđuju i signifikantne vrijednosti na nivou značajnosti $\mathrm{p}<0.05$. Prilikom utvrđivanja kvan- titativnih promjena antropometrijskih parametara, očigledna je statistička značajnost kod većine varijabli, sem kod mjera bikristalni raspon, biakromijalni raspon i obim natkoljenice. 


\section{Diskusija}

Osnovni cilj ovog istraživanja je da se utvrdi da li postoje statistički značajne razlike u nivou antropometrijskih karakteristika između sportista različitog sportskog usmjerenja (košarka i odbojka), odnosno da se utvrde razlike u promjenama antropometrijskih karakteristika sportista. Uzorak od ukupno 50 ispitanika, muškog pola podijeljenih na dva subuzorka. Prvi subuzorak su činili 25 dječaka članova Košarkaškog kluba „Sutjeska“, prosječne starsoti $13.95 \pm 4.28$ i drugi subuzorak su činili 25 dječaka članova Odbojkaškog kluba „Volley star“, iz Nikšića, prosječne starosti 14.05 \pm 7.15 . Rezultati su dobijeni korišćenjem baterije od 12 testova u prostoru antropometrijskih karakteristika.

$\mathrm{Na}$ osnovu uvida u dobijene deskriptivne parametre prosječna tjelesna visina i tjelesna masa košarkaša obuhvaćenih ovom studijom ( $180.58 \mathrm{~cm}$ i $65.32 \mathrm{~kg})$ su nešto više vrijednosti nego prosječna tjelesna visina i masa tijela košarkaša Srbije istog uzrasta $(171.57 \mathrm{~cm}$ i $59.97 \mathrm{~kg})$ koje nalazimo u predhodnim istraživanjima (Jakovljević, Karalejic, Pajić, Gardasević, \& Mandic, 2011). Ovi podaci su dokaz da je proces selekcije košarkaša obuhvaćenih ovom studijom dobro obavljen, a dokaz dobre selekcije i dobrog rada je to što je kadetska reprezentacija Crne Gore na Evropskom prvenstvu 2017. godine savladala vršnjake iz Srbije i obezbijedila istorijsku srebrenu medalju. Košarka u morfološkom prostoru zahtijeva igrače koji imaju veću tjelesnu visinu, jer znamo da je košarka igra nadprosječno visokih ljudi, zato se od samog početka vrši određena selekcija. U svojoj specifikaciji uspjeha na prvo a samim tim i najvažnije mjesto autori stavljaju upravo antropometrijske karakteristike košarkaša (Karalejic i Jakovljevic, 2001) i to tjelesnu visinu, a zatim masu tijela koja je takođe od velike važnosti u košarci. Na osnovu dobijenih deskriptivnih parametara ovog istraživanja prosječna tjelesna visina odbojkaša je $178.58 \mathrm{~cm}$, a masa tijela odbojkaša je $66.28 \mathrm{~kg}$, pa vidimo da oni imaju nešto niže vrijednosti u odnosu na reprezentativce Srbije istog uzrasta (Bogdanovic et al., 2014) gdje je prosječna tjelesna visina bila $181.87 \mathrm{~cm}$ a masa tijela je iznosila $70.53 \mathrm{~kg}$. Možda je to osnovni razlog zašto crnogorski odbojkaši nijesu uspješni na međunarodnim takmičenjima kao srbijanski odbojkaši sa kojima je vršeno poređenje. Na osnovu navedenog stručnjaci iz odbojke bi trebalo da više vode računa o selekciji jer imaju populaciju koja je veoma visoka (Bjelica, i sar. 2016a; Bjelica, i sar. 2016b; Masanovic, 2017; Vukotic, 2018a; Vukotic, 2018b; Masanovic, 2018b).

Može se zaključiti da kod primijenjenog sistema antropometrijskih mjera postoje statistički značajne razlike u kvantitativnim promjenama sto se može vidjeti na osnovu rezultata T-testa za nezavisne uzorke. Dobijeni rezultati samo dijelom potvrđuju važnost longitudinalne dimenzionalnosti skeleta, u razlikovanju selekcionisanih košarakaša i odbojkaša kadetskog uzrasta (Katic, Grgantov, i Jurko, 2006), jer razlike ukazuju na povezanost rasta i razvoja i uspješnosti u igri kod mladih košarkaša i odbojkaša (Vukotic,2010). U sportskoj praksi dobro je poznat problem prerane specijalizacije kao i neuvažavanja fiziološke zrelosti (Bjelica, Popović, i Gardašević, 2016a), što je pogrešno. U cilju procjene krajnjih mogućnosti mladih sportista potrebno je pronaći adekvatan somatotip za određene sportove, nivoe takmičenja i igračke pozicije (Massuca, i Fragoso, 2011), jer navedene sportske igre karakteriše dinamička i vrlo brza igra, sa mnogo eksplozivnih pokreta, i skokova, a sportisti mogu odgovoriti navedenim zahtjevima ako imaju visok nivo razvijenosti morfoloških karakteristika (Gaurav,
Singh, i Singh, 2010; Masanovic, Popovic, i Bjelica, 2018).

Rezultati koji su dobijeni ovim istraživanjem mogu poslužiti kao modelni parametri u procjenjivanim varijablama za sve ostale igrače istog ranga takmičenja u Crnoj Gori, jer su analizirani igrači članovi dva kvalitetna tima kadetskog uzrasta. Treba napomenuti da igrači koje žele uspješno nastupati u ligama gdje se igra najkvalitetnija košarka i odbojka, moraju imati karakteristike utvrđene standardima za taj sport, a to se prije svega ogleda u antropometrijskim karakteristikama.

\section{Acknowledgements}

There are no acknowledgements.

\section{Conflict of Interest}

The authors declare that there are no conflicts of interest.

Received: 1 December 2018 | Accepted: 27 December 2018 | Published: 25 January 2019

\section{References}

Bjelica, D. (2002). Opšti pojmovi sportskog treninga: (skraćena verzija). Podgorica: Crnogorska sportska akademija.

Bjelica, D. (2004). Uticaj sportskog treninga na antropomotoričke sposobnosti: (fudbalskih kadeta Crne Gore). Podgorica: Crnogorska sportska akademija.

Bjelica, D. (2005). Sistematizacija sportskih disciplina i sportski trening. Podgorica: Crnogorska sportska akademija.

Bjelica, D. (2006a). Sportski trening. Podgorica: Crnogorska sportska akademija.

Bjelica, D. (2006b). Teorijske osnove tjelesnog i zdrastvenog obrazovanja. Podgorica: Crnogorska sportska akademija.

Bjelica, D. (2013). Teorija sportskog treninga. Podgorica: Univerzitet Crne Gore.

Bjelica, D., \& Fratrić, F. (2011). Sportski trening: teorija, metodika i dijagnostika. Nikšić: Fakultet za sport i fizičko vaspitanje.

Bjelica, D., i Krivokapic, D. (2012). Uticaj fizičkog vježbanja na psihomotorne funkcije starijih osoba. Zbornik radova Druge međunarodne konferencije Sportske nauke i zdravlje, Banja Luka: Panaevropski univerzitet APEIRON, 191-196.

Bjelica, D., i Krivokapic, D. (2010). Teorijske osnove fizičke kulture. Nikšić: Fakultet za sport i fizičko vaspitanje Univerziteta Crne Gore.

Bjelica, D., i Krivokapic, D. (2011). Teorija igre. Nikšić: Fakultet za sport i fizičko vaspitanje Univerziteta Crne Gore.

Bjelica, D., Popovic, S., i Gardasevic, J. (2016a). Modeli fizičke pripreme vrhunskih sportaša i doziranje opterećenja. Zbornik radova 14. godišnje međunarodne konferencije "Kondicijska priprema sportaša" (185-189), Zagreb: Udruga kondicijskih trenera Hrvatske.

Bjelica, D., Popovic, S., i Gardasevic, J. (2016b). Opći principi planiranja i programiranja fizičkih priprema sportaša. Zbornik radova 14. godišnje međunarodne konferencije "Kondicijska priprema sportaša" (190-192), Zagreb: Udruga kondicijskih trenera Hrvatske.

Bogdanovic, Z., Smajic, M., Jaksic, D., Obradovic, M., Gogic, A., Vidakovic, H.M., Ljubisavljevic, M., Draskovic, V., Visnjic, S., Mekic, H., Stankovic, R., Ivancic, G., \& Popovic, S. (2014). Lumbar and abdominal muscles isometric potential in volleyball cadets. Int. J. Morphol., 32(3), 1036-1042.

Gardasevic, J., i Bjelica, D. (2013). Efekti programiranog trenažnog rada u trajanju od šest nedjelja na transformaciju fleksibilnosti kod fudbalera kadetskog uzrasta. Sport Mont, 11(37-39), 212-217.

Gardasevic, J., i Bjelica, D. (2014). Efekti rada u pripremnom periodu na brzinu vođenja lopte petnaestogodišnjih fudbalera. Sport Mont, 12(40-42), 160-166.

Gardasevic, J., Popovic, S., \& Bjelica, D. (2016). After preparation period ball shooting accuracy at players U15. In Abstract Book of the 8th Conference for Youth Sport (88), Ljubljana: University of Ljubljana, Faculty of Sport.

Gaurav, V., Singh, M., \& Singh, S. (2010). Anthropometric characteristics, somatotyping and body composition of volleyball and basketball players. Journal of Physical Education and Sports Management 1(3), 28-32.

Jakovljevic, S., Karalejic, M., Pajić, Z., Gardasević, B., \& Mandic, R. (2011). The influence of antropometric characteristics on the agility abilities of 14 year - old elite male basketball players. Facta Universitatis - Series: Phisical education and Sport, 9(2), 141-149.

Karalejic, M., Jakvoljevic, S. (2001). Osnove košarke. Beograd: Fakultet sporta i fiziçkog vaspitanja

Katic, R., Grgantov, Z., \& Jurko, D. (2006) Motor structures in female volleyball players aged 14-17 according to technique quality and performance. Collegium Antropologicum, 30(1), 103-112. 
Masanovic, B. (2008). Determination of body composition of athletes. Unpublished Master Thesis. Novi Sad: Faculty of Sport and Physical Education.

Masanovic, B. (2009). Differences of anthropometrical status on top leve handball players and non sportsmen. Sport Mont, 6(18-19-20), 569-575.

Masanovic, B. (2015). Anthropological indicators of the proprioceptive training success with football players and students aged 15-16 years. Unpublished Doctoral Dissertation. Novi Sad: University of Novi Sad.

Masanovic, B. (2017). Relationship between arm span measurements and body height in Dinaric Alpes population: A systematic review. Journal of Anthropology of Sport and Physical Education, 1(1), 33-37. doi: 10.26773/ jaspe. 171006

Masanovic, B. (2018a). Comparative study of anthropometric measurement and body composition between junior basketball and volleyball players from Serbian national league. Sport Mont, 16(3), 19-24. doi: 10.26773/ smj.181004

Masanovic, B. (2018b). Standing height and its estimation utilizing arm spam and foot length measurements in dinaric alps population: a systematic review. Sport Mont, 16(2), 101-106. doi: 10.26773/smj.180619

Masanovic, B., Milosevic, Z., \& Corluka, M. (2018). Comparative Study of Anthropometric Measurement and Body Composition between Junio Handball and Volleyball Players from Serbian National League. International Journal of Applied Exercise Physiology, 7(4), 1-6. https://doi. org/10.30472/ijaep.v7i4.313

Masanovic, B., Popovic, S., \& Bjelica, D. (2018). Comparative Study of Anthropometric Measurement and Body Composition Between Junior Socce and Volleyball Players From National League. In Book of Abstracts 15th International Scientific Conference on Transformation Process in Sport "Sport Performance" (58), Podgorica: Montenegrin Sports Academy.

Masanovic, B., Vukotic, M., \& Vukasevic, V. (2018). Comparative study of morphological characteristics and body composition between elite basketball players from different regions. Journal of Anthropology of Sport and Physical Education, 2(4), 103-107. doi: 10.26773/jaspe.181019

Masanovic, B., Vukotić, M., Popovic, S., Bjelica, D. (2018). Comparative study of anthropometric measurement and body composition between junior basketball and volleyball players from Serbian national league. World Congress of Performance Analysis of Sport XII (340). Croatia: University of Zagreb.

Massuca, L. \& Fragoso, I. (2011). Study of Portuguese handball players of diff erent playing status. A morphological and biosocial perspective. Biology of Sport, 28(1),37-44.

Mišigoj-Duraković, M., Matkovic, B., \& Medved, R. (1995). Morfološka antropometrija u športu. Morphological anthropometry in sports. Zagreb, Croatia: Fakultet za fizičku kulturu.

Popovic, S. (2017). Local Geographical Differences in Adult Body Height in Montenegro. Montenegrin Journal of Sports Science and Medicine, 6(1), 81-87.
Popovic, S., Akpinar, S., Jaksic, D., Matic, R., \& Bjelica, D. (2013). Comparative Study of Anthropometric Measurement and Body Composition between Elite Soccer and Basketball Players. International Journal of Morphology, 31(2), 461-467.

Popovic, S., Bjelica, D., Molnar, S. Jaksic, D, \& Akpinar, S. (2013). Body height and its estimation utilizing arm span Measurements in serbian adults. Int. J. Morphol., 31(1), 271-279.

Popovic, S., Bjelica, D., Vukotic, M., \& Masanovic, B. (2018). Describing Physical Activity Profile of Older Montenegrin Females Using the International Physical Activity Questionnaire (IPAQ). In Book of Abstracts 15th International Scientific Conference on Transformation Process in Sport "Sport Performance" (60-61), Podgorica: Montenegrin Sports Academy.

Popovic. S., Bjelica, D., Jaksic, D., \& Hadzic, R. (2014). Comparative Study of Anthropometric Measurement and Body Composition between Elite Soccer and Volleyball Players. International Journal of Morphology, 32(1), 267-274.

Vukasevic, V., Vukotic, M., \& Masanovic, B. (2018). Comparative study of morphological characteristics and body composition between basketball players from second leagues in Montenegro and Serbia. Journal of Anthropology of Sport and Physical Education, 2(3), 21-25. doi: 10.26773/ jaspe.180704

Vukotic, M. (2018). Comparative analysis of antropmtric indicators of sportisis of different soprts quidance. In Book of Abstracts 15th International Scientific Conference on Transformation Process in Sport "Sport Performance" (75-76), Podgorica: Montenegrin Sports Academy.

Vukotic, M. (2010). Nivo morfoloških karakteristika, motoričkih i funkcionalnih sposobnosti sportista različitog sportskog usmjerenja. Neobjavljena magistarska teza. Nikšić: Fakultet za sport i fizičko vaspitanje.

Vukotic, M. (2011). Differences of anthropometric characteristic and motor abilities of different sport orientation. Sport Mont, 9(28-29-30), 112-118.

Vukotic, M. (2018a). Body Height and its Estimation Utilizing Arm Span Measurements in Male and Female Adolescents from Danilovgrad and Cetinje. Journal of Anthropology of Sport and Physical Education, 2(3), 117-121.

Vukotic, M., (2018b). Body Height and its Estimation Utilizing Arm Span Measurements in Male and Female Adolescents from Northern Region in Montenegro. Journal of Anthropology of Sport and Physical Education, 2(3), 73-77.

Vukotic, M., Corluka, M., Vasiljevic, I., \& Bubanja, M. (2018). Differences in the Morphological Characteristics and Body Composition of Handball Players WHC Levalea in Montenegro and WHC Grude in Bosnia and Herzegovina. J. Anthr. Sport Phys. Educ. 2(2), 49-53 Original scientific paper DOI: 10.26773/jaspe.180409 